\title{
Statistical analysis of sub-zero temperature effects on fatigue strength of welded joints
}

\author{
Moritz Braun ${ }^{1}[$
}

Received: 2 August 2021 / Accepted: 4 November 2021 / Published online: 12 November 2021

(c) The Author(s) 2021

\begin{abstract}
Ships and offshore structures in Arctic environments are exposed to severe environmental actions and sub-zero temperatures. Thus, the design of such structures has to account for the Arctic environment and must be cost-efficient at the same time. A vital part of the design process is to ensure that fatigue-induced failure does not occur in the lifetime of the structure. While effects of high temperatures on material behavior are well covered in international standards and guidelines, there is no comprehensive guidance for sub-zero temperature fatigue strength assessment. Additionally, stress-life (S-N) test data of welded joints at sub-zero temperatures is particularly scarce. Hence, this study presents an extensive review of recent test results of various weld details tested in the range of -50 to $20^{\circ} \mathrm{C}$. This data could build the basis for future considerations of temperature effects in fatigue design guidelines and recommendations. For this purpose, the fatigue test results are submitted to a rigorous statistically assessment—including a summary of the limitations of current design guidelines with respect to sub-zero temperature effects.
\end{abstract}

Keywords Sub-zero temperatures - Arctic conditions - Fatigue transition temperature $\cdot$ Temperature dependence of fatigue curves $\cdot$ Ductile-brittle transition $\cdot$ Fatigue testing

\section{Introduction}

In recent years, there has been a steady increase in operations in Arctic environments-in connection with the Arctic shipping routes and a growing interest in setting up wind turbines in yet unexploited areas such as the northern Baltic Sea. Other structures include oil and gas rigs, lighthouses, and navigational aids. These structures are exposed to drifting sea ice and sub-zero temperatures, in addition to the waves, wind, and current. Thus, the design of such structures has to account for static and dynamic structural responses that are different from other engineering structures. Because of the at times more severe load effects in ice-covered regions, e.g., due to ice-induced vibrations [1-4], and because of the

Recommended for publication by Commission XIII - Fatigue of Welded Components and Structures

Moritz Braun

moritz.br@tuhh.de

1 Institute for Ship Structural Design and Analysis, Hamburg University of Technology, Am Schwarzenberg Campus 4(C), 21073 Hamburg, Germany potential consequences for the fragile natural environment in the Arctic, a crucial part of the design process is to ensure that no fatigue-induced failure occurs during the lifetime of the structure. Among those challenges, fatigue of welded joints at sub-zero temperatures was recently determined to be a major knowledge gap [5].

While effects of high temperatures on material behavior are well covered in international standards and guidelines, there is no comprehensive guidance for sub-zero temperature fatigue strength assessment of welded joints. This is likely related to the small number of publications concerning fatigue of welded steel joints at sub-zero temperatures, see [6-17]. Moreover, the majority of studies focuses on fatigue crack growth (FCG) rate testing for cryogenic applications and butt-welded joints. In fact, the majority of studies investigating sub-zero temperature fatigue behavior of ferritic materials observed an increase of fatigue strength before a sudden drop. This effect, which is related to the well-known fracture ductile-brittle transition, will be briefly explained in Sect. 2. Currently, stress-life $(\mathrm{S}-\mathrm{N})$ test data of welded joints at sub-zero temperatures is particularly scarce. Hence, this study presents a comprehensive review of recent test results of various weld details tested in the range of 20 
to $-50^{\circ} \mathrm{C}$, see Sect. 3. This $\mathrm{S}-\mathrm{N}$ data can be used as basis for future considerations of temperature effects in fatigue design guidelines and recommendations. Finally, to quantify the effect of temperature on fatigue strength, the data is statistically analyzed in Sect. 4 by assessing the correlation between test temperature and number of cycles to failure, and bootstrapping. Additionally, a correlation to specimen misalignment is included to highlight impact of temperature on fatigue strength.

\section{State of the art}

\subsection{Temperature effects on material behavior}

Similar to the fracture ductile-brittle transition, a transition in fatigue fracture behavior is observed in materials with body-centered cubic crystal structure, which is called fatigue ductile-brittle transition (FDBT) and happens at the fatigue transition temperature (FTT). Below the FTT, a sudden acceleration in fatigue crack propagation and an increase in threshold stress intensity factor range $\Delta K_{t h}$ are typically observed [18-20], see Fig. 1. Kawasaki [18] was one of the first to relate this effect to the fracture ductile-brittle transition temperature. More recently, Alvaro et al. [19] presented a literature review of the current understanding of the underlying mechanism, including the effect of sub-zero temperatures on fatigue crack initiation and propagation. A number of recently published studies led to a better understanding of the change of fatigue crack growth behavior at sub-zero temperatures and a correlation of FTT and ductile-brittle transition temperature (DBTT) in base and weld-simulated materials, see $[20,21]$. So far, there is very limited data on actual welded materials, which is why the effects are less known and not considered in international standards.

It is often assumed that low temperatures have no detrimental effect on fatigue properties as long as sufficient fracture toughness is ensured, see Hauge et al. [22]; however, from base material tests, it is known that FTT and DBTT are close to each other (i.e., within a range of $20^{\circ} \mathrm{C}$ $[20,21])$. It can consequently not be assumed that fracture toughness requirements alone are sufficient to ensure structural integrity at low operating temperatures. To get a better understanding of the fatigue behavior at sub-zero temperatures, more studies on welded connections including $\mathrm{S}-\mathrm{N}$ test results are required. Based on the observed fatigue transition behavior and the course of FCG rate curves (Fig. 1a, the effect on S-N curves is expected to be similar to the schematic presentation in Fig. $1 \mathrm{~b}$.

In their review, Alvaro et al. [19] related the change in FCG behavior to a change in dominant crack growth behavior from plastic blunting and tearing to cleavagecontrolled brittle fracture. Additionally, differences in crack initiation behavior are linked to variations in stacking fault energy with temperature. Hence, differences in fatigue strength are expected due to the microstructure surrounding a failure initiation location [23].

It is typically assumed that the slopes of $\mathrm{S}-\mathrm{N}$ curves of welded joints $(k)$ are similar to the slopes of FCG rate curves $(m)$, as the fatigue life of welded joints is dominated by fatigue crack propagation. It can also be shown that the fatigue limit $\left(\Delta \sigma_{R}\right)$ observed in $\mathrm{S}-\mathrm{N}$ tests is related to the threshold stress intensity factor range $\left(\Delta K_{t h}\right)$. Toward the low-cycle fatigue regime, a correlation between yield strength and endurable stress range is expected. As yield strengths are known to increase with decreasing test temperature even below the DBTT [24-26], it can be assumed that the endurable stress range increases as well, yet there is not enough literature data available to verify this expectation. In contrast, plastic strains are known to initiate brittle fracture once a crack has formed. It is thus expected that the S-N curves of welded joints are in between those at RT and at temperatures between RT and FTT.
Fig. 1 Schematic representation of the effect of low temperature on fatigue crack growth curves (a) based on $[5,19]$ and corresponding $\mathrm{S}-\mathrm{N}$ curves of welded joints (b), taken from Braun [23]

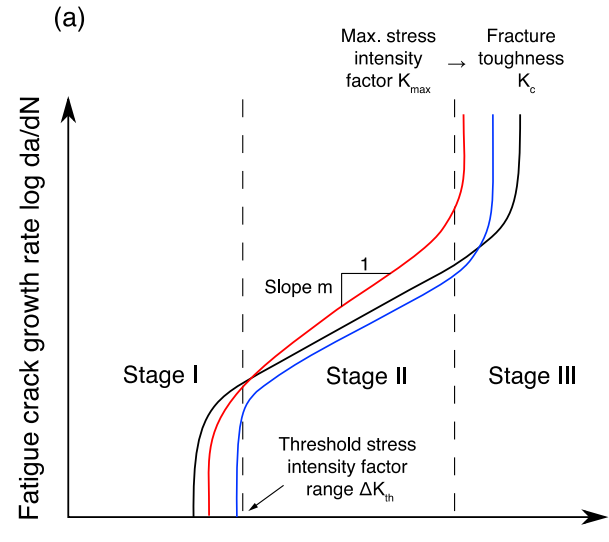

Stress intensity factor range log $\Delta K$ (b)

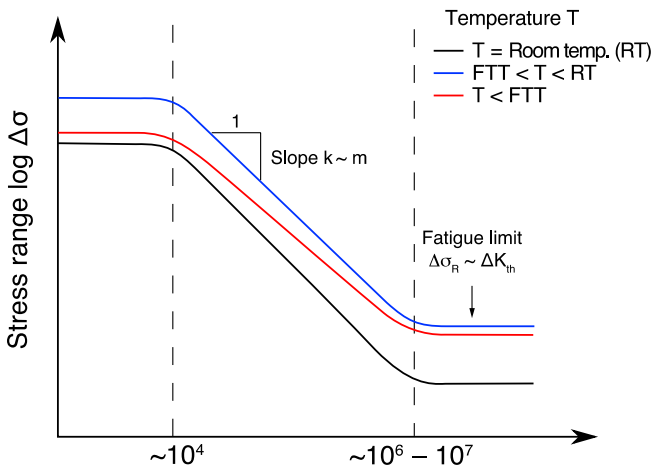

Number of cycles $\log \mathrm{N}$ 


\subsection{Consideration of temperature effects in current fatigue design guidelines and standards}

As initially mentioned, effects of sub-zero temperatures on fatigue strength of welded joints are currently not considered in any fatigue design guidelines and standards, see [27-31]. On the contrary, adverse effects of high temperatures are typically included and can thus be used as a reference. The IIW recommendations [27] and BS7910 [28] correlate fatigue design class at high temperature $\left(F A T_{H T}\right)$ to the change of Young's modulus at high temperatures $\left(E_{H T}\right)$ with:

$F A T_{H T}=F A T_{20^{\circ} \mathrm{C}} \frac{E_{H T}}{E_{20^{\circ} \mathrm{C}}}$

where $F A T_{20^{\circ} \mathrm{C}}$ and $E_{20^{\circ} \mathrm{C}}$ are the fatigue design class and the Young's modulus at $20^{\circ} \mathrm{C}$, respectively. In fact, BS7910 [28] uses this formula for changes in the threshold stress intensity factor ranges of steels. The German FKM guideline [32] also includes a correction function for high temperatures $(T)$ above $100{ }^{\circ} \mathrm{C}$, which is related to the fatigue strength at $20^{\circ} \mathrm{C}\left(\sigma_{w, T=20^{\circ} \mathrm{C}}\right)$. Interestingly, a constant fatigue strength is assumed between 20 and $100{ }^{\circ} \mathrm{C}$. Above $100{ }^{\circ} \mathrm{C}$, the fatigue strength $\left(\sigma_{w}(T)\right)$ shall be corrected using the following functions.

$\sigma_{w}(T)=K_{T, D} \sigma_{w, T=20^{\circ} \mathrm{C}}$

$K_{T, D}=1-1.4 \cdot 10^{-3} \cdot(T-100)$; for $T>100^{\circ} \mathrm{C}$

Applying the correction function of the FKM guideline to sub-zero temperatures, a higher change in fatigue strength was estimated in Braun [23] (at $-50{ }^{\circ} \mathrm{C}$, i.e., $2 \%$ and $10 \%$ according to the IIW recommendations [27] and BS7910 [28], and FKM guideline [32], respectively), which matched the fatigue test results better (on average about 15\%). Finally, no guidance is given in standards on how temperature effects affect fatigue assessment by means of local fatigue assessment concepts [23, 33].

Fig. 2 Schematic presentation of fatigue test specimens with dimensions, extended from Braun et al. [34] and taken from Braun [23]

\section{Fatigue test data of welded joints obtained at sub-zero temperatures}

\subsection{Materials and test specimens}

Three different weld details, three steel types, and two welding methods were selected to rule out uncertainties related to the former and to create a large database for the assessment of sub-zero temperature effects on fatigue of welded joints. The steel types are typical structural steels that are commonly used to build ships and offshore structures $(\mathrm{S} 235 \mathrm{~J} 2+\mathrm{N}, \mathrm{S} 355 \mathrm{~J} 2+\mathrm{N})$ and a thermomechanically rolled, fine-grain structural steel $(\mathrm{S} 500 \mathrm{G} 1+\mathrm{M})$. The weld details include butt-welded joints, transversal stiffener specimens, and cruciform joints with weld root failure. The S235 and S500 specimens were flux-cored arc welded-using AWS A5.20: E71T-1 M-J and AWS A5.29: E81T1-Ni1M-J H4 wires, respectively. The $\mathrm{S} 355$ specimens were welded using submerged arc welding and an AWS A5.17: EM $12 \mathrm{~K}$ wire. The steel was saw-cut into specimens of $500 \mathrm{~mm}$ in length and $50 \mathrm{~mm}$ in width (40 $\mathrm{mm}$ for the butt-welded joints), and $10 \mathrm{~mm}$ in thickness, see Fig. 2.

The measured tensile test results and the Charpy V-notch impact toughness results of the three steels are listed in Table 1 and Fig. 3, respectively. The assumed DBTT is based on the $27 \mathrm{~J}$ criterion for S235 and S355 steel and $50 \mathrm{~J}$ $\left(\sigma_{Y S} / 10\right)$ for the S500 steel, see DNVGL-OS-B101 [35]. Unsurprisingly, the base material of the fine-grained structural steel S500G1 + M has the highest Charpy notch impact toughness; however, all three steels exhibit high toughness even at temperatures below $-50{ }^{\circ} \mathrm{C}$. For the two steels (S235

Table 1 Tensile test results for the different types of steel considered, taken from Braun et al. [26]

\begin{tabular}{llll}
\hline Steel type & $\begin{array}{l}\text { Yield strength } \\
\sigma_{Y S}[\mathrm{MPa}]\end{array}$ & $\begin{array}{l}\text { Ultimate tensile } \\
\text { strength } \sigma_{U T S}[\mathrm{MPa}]\end{array}$ & $\begin{array}{l}\text { Elongation at } \\
\text { fracture } e_{f}[\%]\end{array}$ \\
\hline S235J2+N & 356 & 445 & 38 \\
S355J2+N & 434 & 544 & 29 \\
S500G1+M & 595 & 651 & 23 \\
\hline
\end{tabular}

(a) Butt-welded joints

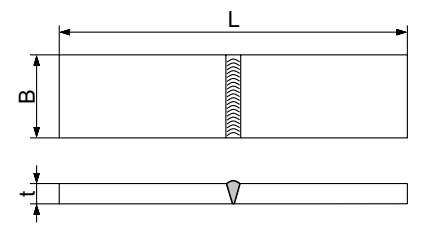

$\mathrm{t}=10 \mathrm{~mm}$

$\mathrm{B}=40 \mathrm{~mm}$

$\mathrm{L}=500 \mathrm{~mm}$ (b) Cruciform joints

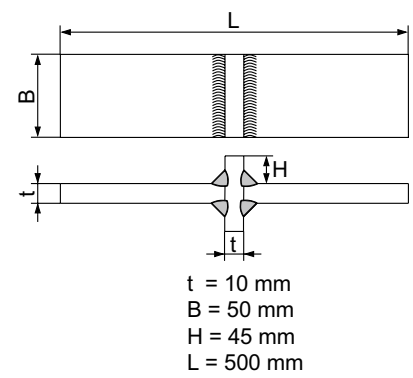

(c) Transversal stiffener

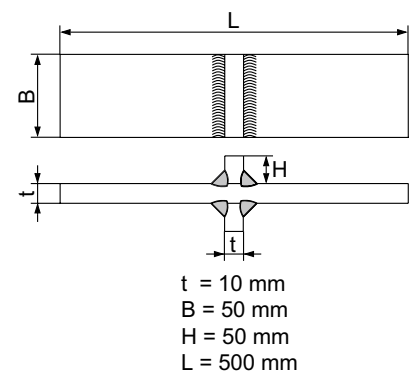


Fig. 3 Charpy V-notch impact toughness results, adopted from Braun [23] and Braun et al. [26]
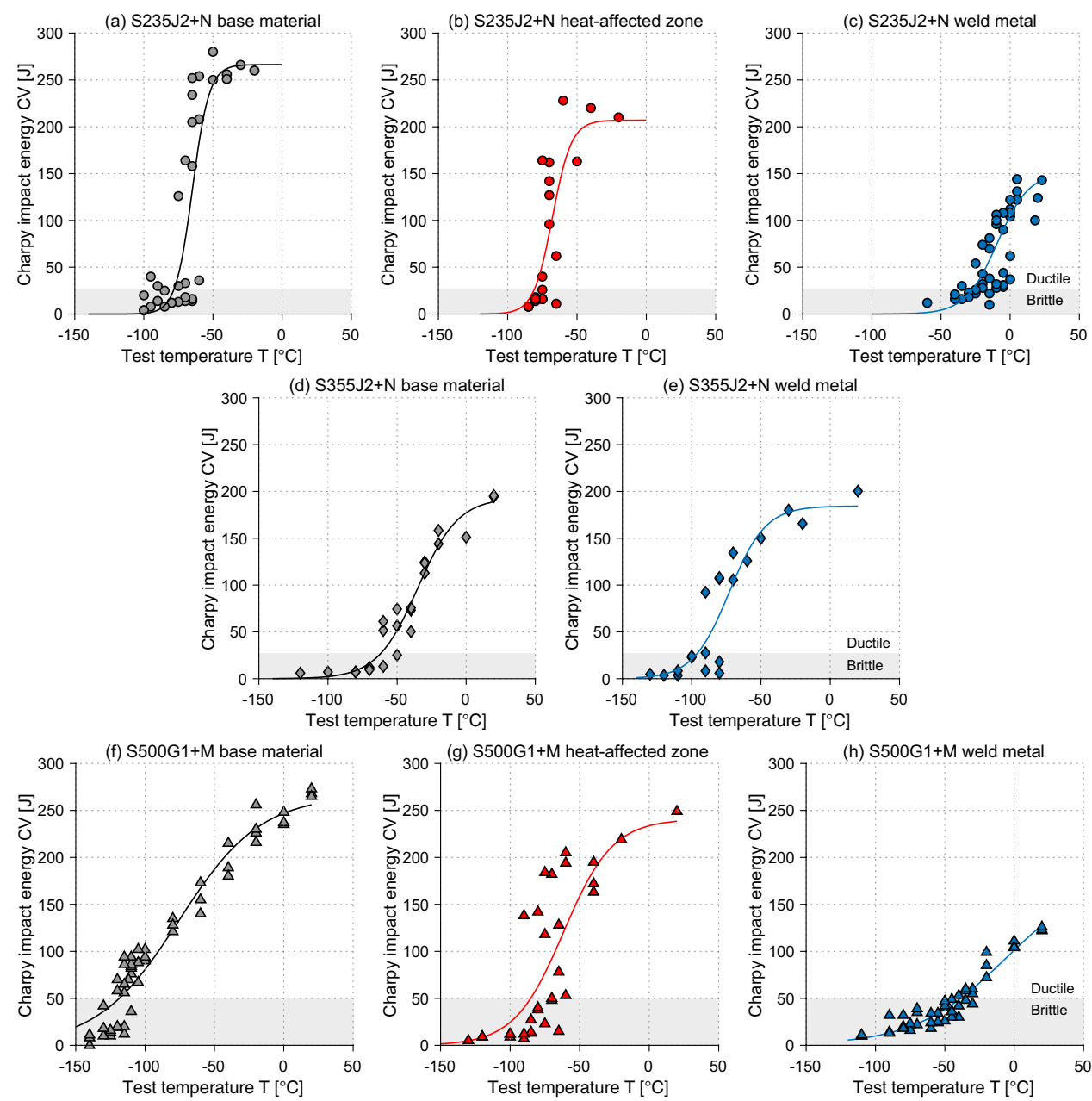

and S500) joined by flux-cored arc welding, a low toughness is observed in the middle of the weld metal. In contrast, a higher toughness is observed in the weld metal of the submerged arc-welded S355 joints compared to the base material. This is in agreement with a number of studies that compared the toughness of joints made by the two welding processes, cf. [36-38].

Each fatigue test series consists of at least 10 specimens. Before the fatigue tests, the misalignment and weld geometry of all specimens were measured. For the latter, laser triangulation and the curvature method were applied, see $[39,40]$. This is required since the nominal stress assessment of cruciform joints failing from weld roots is based on the stress acting on the weld. Thus, a precise measurement of the throat thickness of these specimens is crucial.

Fatigue testing was carried out under axial loading in the temperature chamber at a frequency around $33 \mathrm{~Hz}$ and a stress ratio of $R=0$. Full fracture of a specimen was used as the failure criterion. Cooling was achieved by vaporizing liquid nitrogen. During the test, the temperature in the chamber and on the specimen was monitored by temperature gauges inside the climate chamber and on the specimens.

\subsection{Nominal stress assessment of obtained fatigue test results}

The statistical assessment was performed following the recommendations of the German Welding Association for the assessment of fatigue test data [41] in order to obtain the mean stress-life $(S-N)$ curve with:

$N=2 \times 10^{6}\left(\frac{\Delta \sigma_{n}}{\Delta \sigma_{R}}\right)^{-k}$

where $N$ is the endured number of cycles on the nominal stress range level $\Delta \sigma_{n}$ and $\Delta \sigma_{R}$ as mean reference fatigue strength (survival probability of $50 \%$ ) at $2 \times 10^{6}$ cycles. The curves were derived using a fixed slope exponent $k=$ 3 according to the IIW recommendations [27]. Except for the S355 submerged arc-welded butt joints, tests were performed at room temperature (RT), $-20^{\circ} \mathrm{C}$, and $-50^{\circ} \mathrm{C}$. The S355 specimens were only tested at RT and $-20^{\circ} \mathrm{C}$. The nominal stress fatigue results of the test program are presented in Fig. 4, including the corresponding fatigue design curves (FAT classes). Since the effect of the cyclic mean 

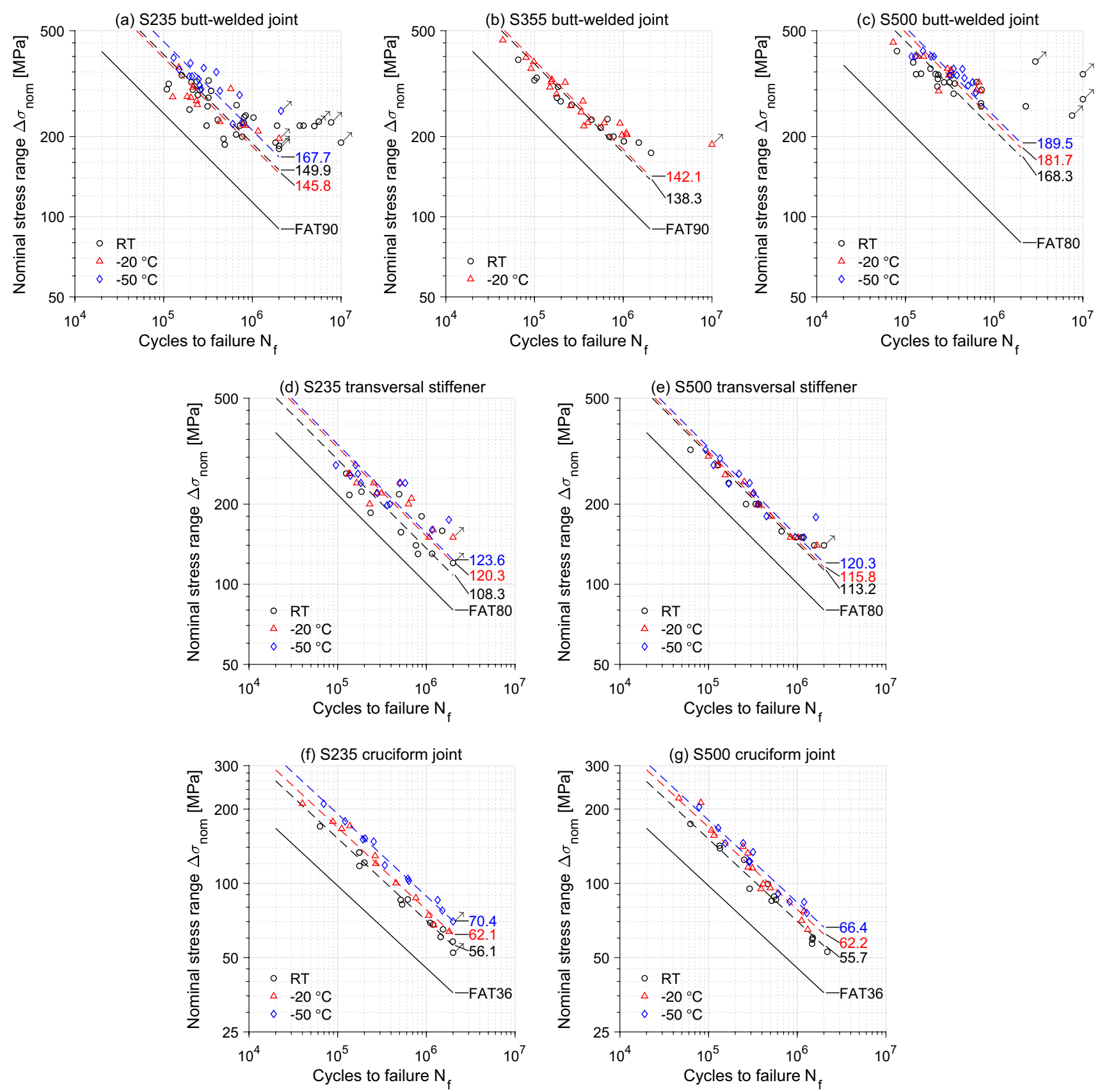

Fig. 4 Fatigue test results of welded joints at room and sub-zero temperatures for $k=3$ and $R=0$, and corresponding IIW fatigue design curves with run-outs marked by arrows, data from [26, 42, 43]

stress at sub-zero temperatures could be different than at room temperature, no correction for the higher stress ratio ( $R=0.5$ for design curves) was performed to present the actual test results.

In the large majority of cases, a higher fatigue strength was obtained at lower temperatures. Only the calculation for the S235 butt-welded joints showed a lower mean fatigue strength at $-20{ }^{\circ} \mathrm{C}$ compared to room temperature.
In Fig. 5, the results of all test series are summarized in a bar chart so as to highlight the fatigue strength improvement relative to room temperature and compared to corresponding room temperature design curves of the IIW recommendations [27]. For this goal, the results-in terms of the mean fatigue strength $\left(\Delta \sigma_{R, 50 \%}(T)\right)$-are normalized by the corresponding mean fatigue strength at room temperature $\Delta \sigma_{R, 50 \%}(T=\mathrm{RT})$ in Fig. 5a and by the corresponding 
Fig. 5 a Ratio of experimental mean $\left(P_{s}=50 \%, N=2 \times 10^{6}\right)$ fatigue strength at sub-zero temperatures to room temperature and $\mathbf{b}$ ratio of experimental to corresponding fatigue strength class $\left(P_{s}=97.7 \%, N=2 \times 10^{6}\right)$, no mean stress correction was applied as this effect was not yet investigated at sub-zero temperatures; extended from Braun [23]

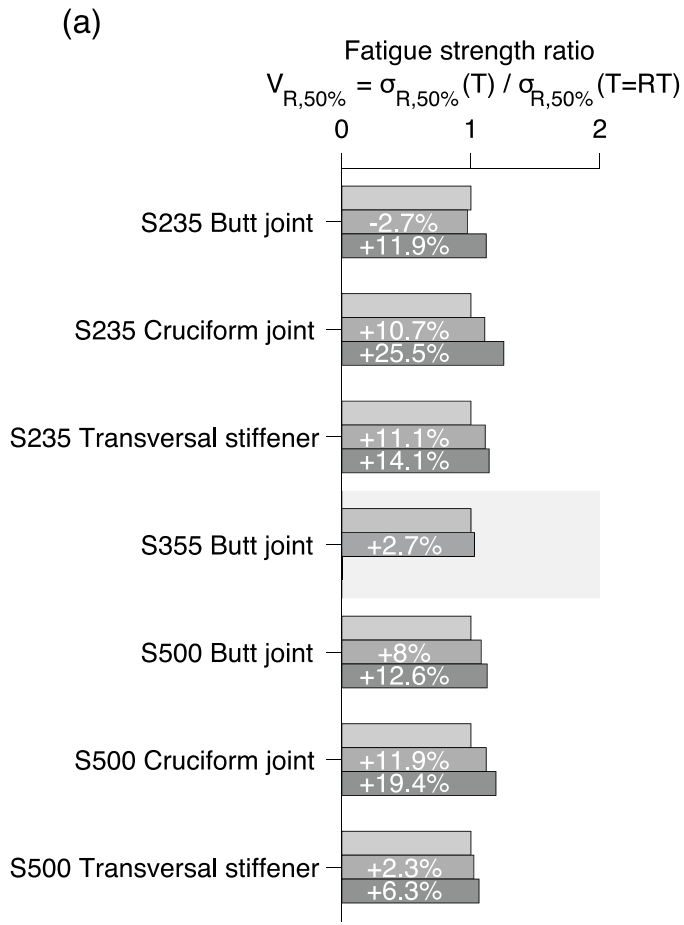

(b)

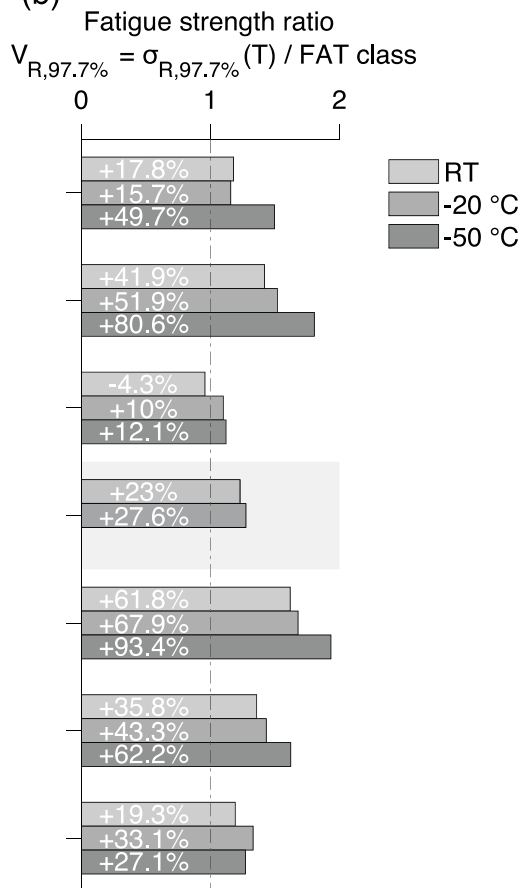

FAT classes (Fig. 5b. As the effect of mean stress on fatigue strength at sub-zero temperatures is not yet investigated, no mean stress correction was applied for the comparison with the current design curves of the IIW recommendations [27]; nevertheless, low residual stress levels can be assumed for all small-scale welded joints. This is confirmed by tests of the fillet welded joints at a high stress ratio $R=0.5$ in Braun et al. [42] and residual stress measurements of the S500 butt joints in Braun et al. [44].

Figure 5 clearly highlights the increase compared to room temperature fatigue strength and fatigue design curves derived from according tests. The results are in line with the decrease in fatigue strength typically observed at high temperatures. Nonetheless, current fatigue design recommendations do not account for this effect.

\section{Statistical assessment of fatigue test results obtained at sub-zero temperatures}

To clearly distinguish the effect of temperature on fatigue strength of welded joints from other influencing factors, a statistical assessment of the test results is presented in the following. For this purpose, correlations between number of cycles to failure $N_{f}$ and test temperatures $T$ are exemplarily assessed. To highlight the effect of test temperature, additional correlations to specimen misalignment are added. In this context, the effect of specimen misalignment is expressed—following the IIW recommendations [27]—as the combined stress magnification factors $k_{m}$ for axial and angular misalignment.

First, to be able to assess the abovementioned correlations, a linear regression model (normal distribution) is fitted to the logarithm of number of cycles to failure. Second, the residuals between test data and regression model are used to determine possible correlation. This is required as the tests were performed at different load levels and can thus not be assessed directly.

To verify the assumption of normally distributed residuals, i.e., to justify the usage of a linear regression model, different tests are performed. For this purpose, both visual and statistical distribution tests are applied. The visual verification of the regression model comprises residual, normal probability, and cumulative distribution function (CDF) plots, see Fig. 6. The chosen statistical distribution test is the Anderson-Darling (AD) test [45], which is considered to be the most precise to verify whether a sample is drawn from a normal distribution [46]. According to the AD test, the data is considered to stem from a normal distribution (null hypothesis) if the test value $A D$ is smaller than the critical value $A D^{*}$ - at a given significance level $\alpha=0.05$ [23]. The goal of the residuals and CDF plots is to verify whether the data is symmetrical (typical for a normal distribution) and whether the empirical CDF is similar to a normal CDF, respectively. If the $\mathrm{AD}$ test confirms the null hypothesis and the residuals appear to be normally distributed, it can be assumed that the fatigue test data is lognormally distributed, see Haibach [47]. 
(a) S235 cruciform joints
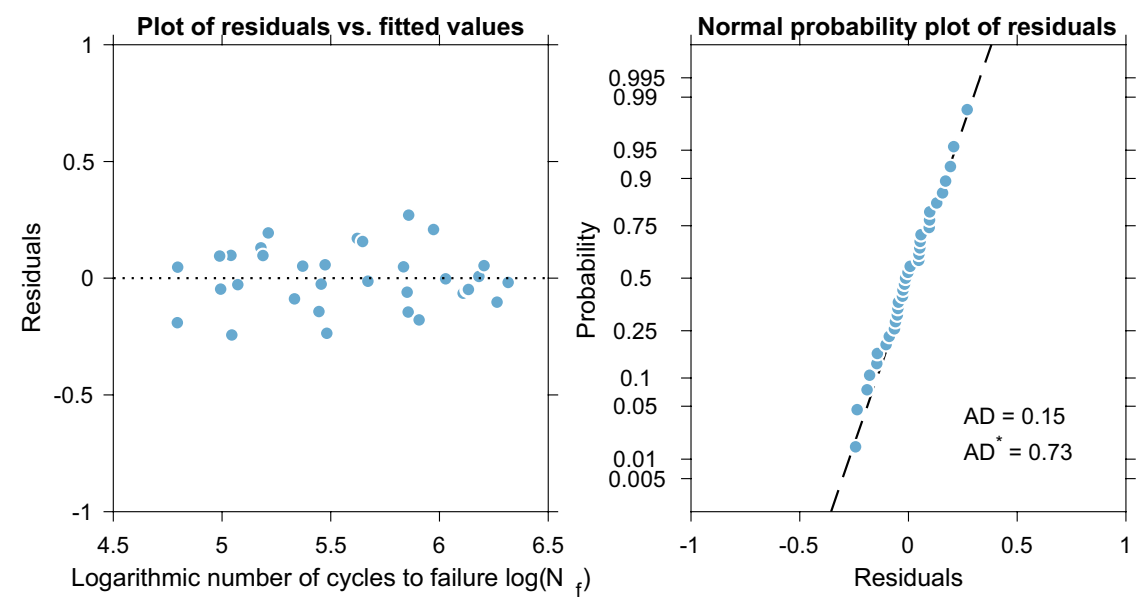

(b) S500 cruciform joints
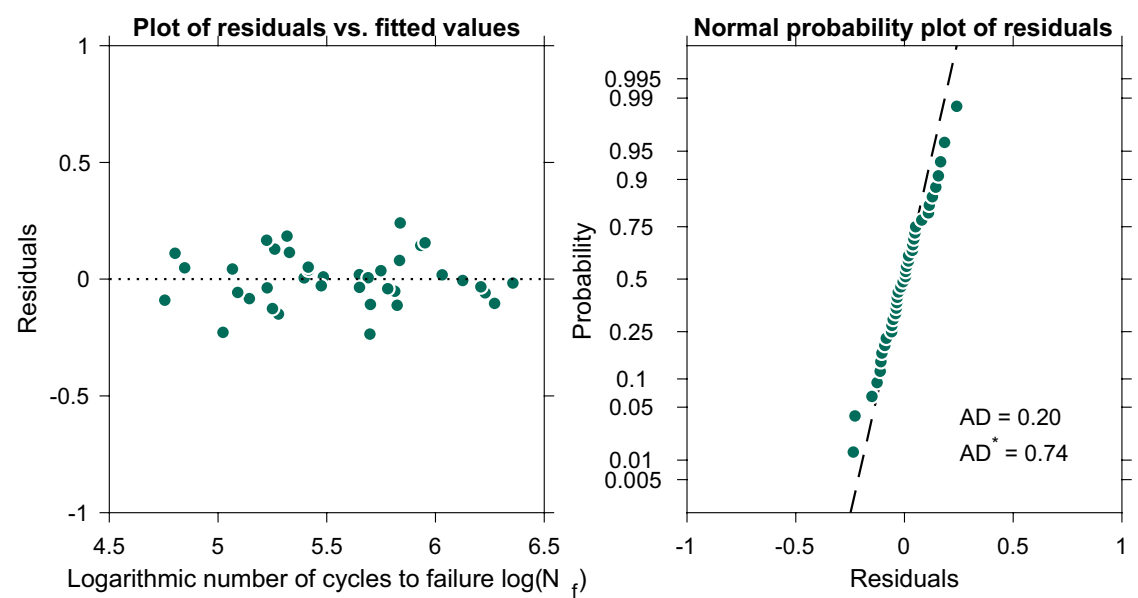
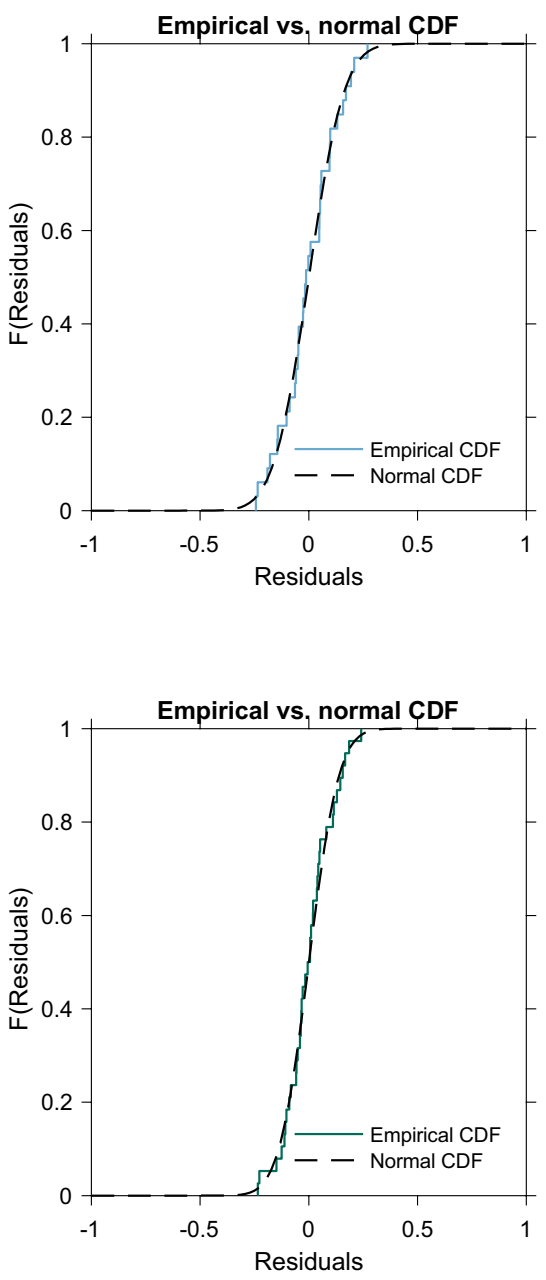

Fig. 6 Difference between residuals and fitted normal distribution, normal probability plot of residuals with results of the Anderson-Darling test, and comparison of cumulative distribution functions for S235J2 + N (a) and S500G1 + M (b) cruciform joints; taken from Braun [23]

Figure 6 presents the exemplary results of the visual and statistical distribution tests for the cruciform joint test data. For both steel types, all three visual assessments indicate a symmetrical function that could be a normal distribution. This result is supported by the AS test results. For both steels, the test value $A D$ is significantly smaller than the critical value $A D^{*}$. Similar results are obtained for the other weld details, see Braun [23].

As the data is considered to be normally distributed, the correlation between the residuals of logarithmic number of cycles to failure and test temperature is subsequently analyzed to determine whether there is a correlation between both quantities. To this goal, Pearson correlation coefficients $r_{x y}$ [48] are calculated, which are typically used to assess linear relations between variables. The assumption of linear relation is based on the results of the fatigue strength comparison with room temperature results that showed an almost linear trend of increasing fatigue strength at sub-zero temperatures. Additionally, correlations between residuals of logarithmic number of cycles to failure $N_{f}$ and stress magnification factors $k_{m}$ are assessed to highlight the significance of test temperature and to assess possible data biases. The results of both correlations are supported by calculations of probability values ( $p$ values) of each fit, i.e., the result of a hypothesis test of no correlation against the alternative hypothesis of a non-zero correlation [23]. According to common practice, $p$ values $(p<0.05)$ are considered to represent a significant correlation coefficient. To evaluate whether the two dependent Pearson correlation coefficients are significantly different, Steiger's $Z$ test [49] is performed. The advantage of this test is that it is easy to perform and suitable for small datasets [50]. For this purpose, the difference of the dependent correlations coefficients is calculated with: 
$\Delta r_{x y}=\left|r_{13}-r_{23}\right|$

where $r_{13}$ and $r_{23}$ are the Pearson correlation coefficients between the test temperature and the residuals of logarithmic number of cycles to failure $N_{f}$, and the stress magnification factors $k_{m}$ and the residuals of logarithmic number of cycles to failure $N_{f}$, respectively. The significance of the difference is assessed using Steiger's [49] formulation of the $p$ value.

The results of the correlation assessments of all weld details with test results at three different test temperatures are presented in Fig. 7, where different colors are used for each test temperature to help distinguish the data. Per definition, a correlation is considered strong if $\left|r_{x y}\right|>0.7$ and moderate if $\left|r_{x y}\right|>0.3$ [51]. Comparing the different test series, the strongest correlation $\left(r_{x y}=-0.80\right)$ between the residuals of logarithmic number of cycles to failure and the test temperature is observed for the S235 cruciform joints. Also, the fatigue strength of S500 cruciform joints showed a high moderate correlation to the test temperature. The (a) S235 Butt-welded joints

$$
\Delta r_{x y}=0.580, p=0.005
$$

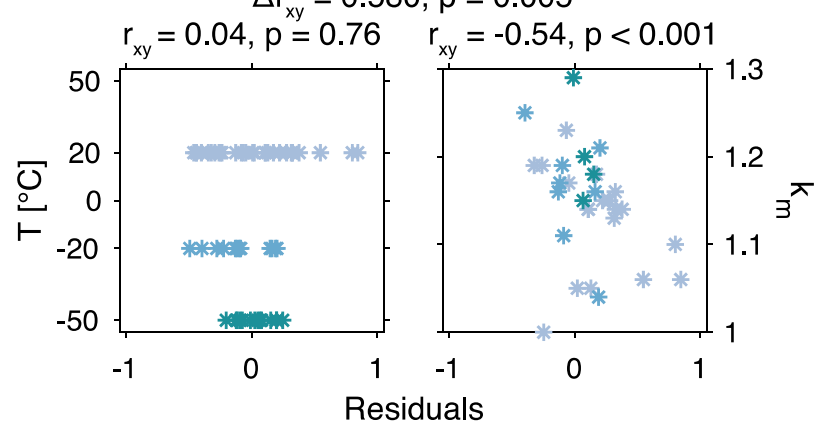

(c) S235 Transversal stiffener

$$
\Delta r_{x y}=-0.344, p=0.193
$$

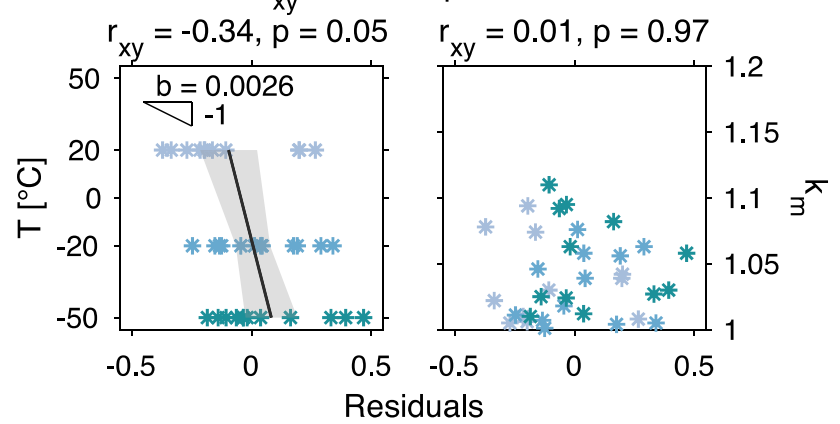

(e) S235 Cruciform joint

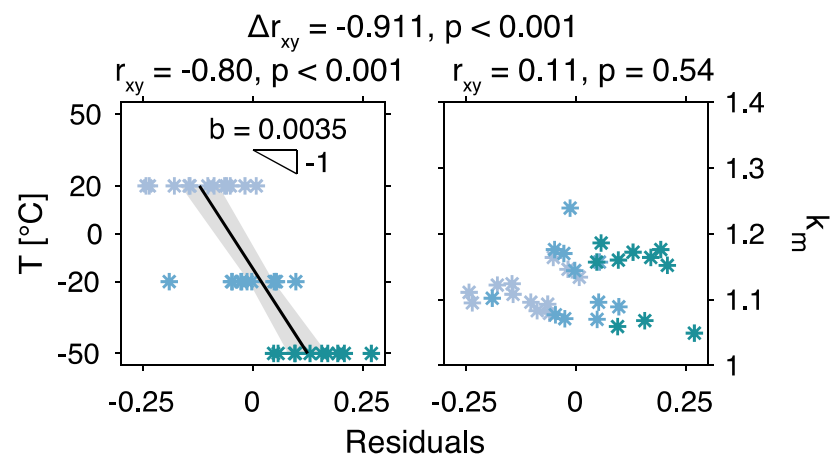

(b) S500 Butt-welded joints

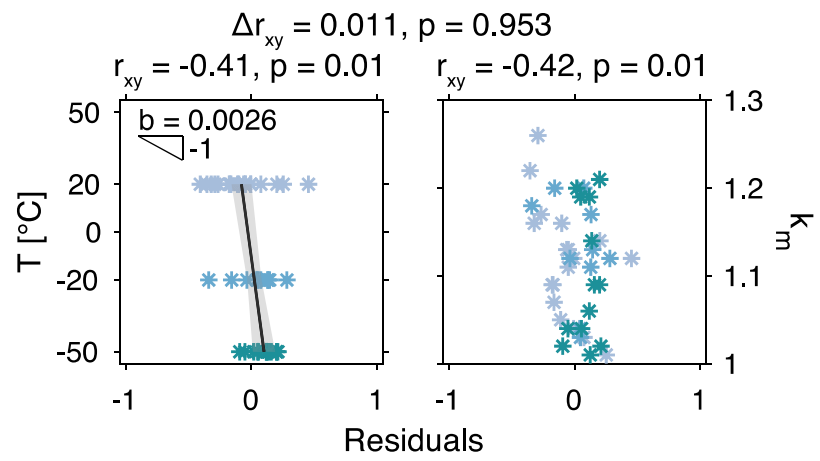

(d) S500 Transversal stiffener

$\Delta r_{x y}=-0.032, p=0.884$

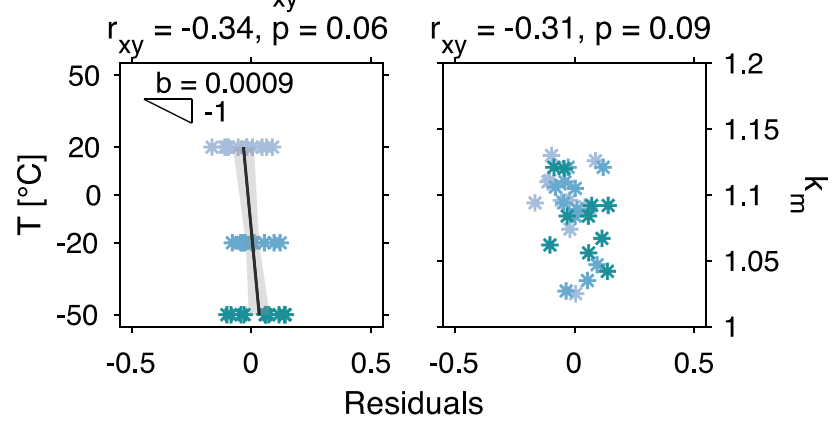

(f) S500 Cruciform joint

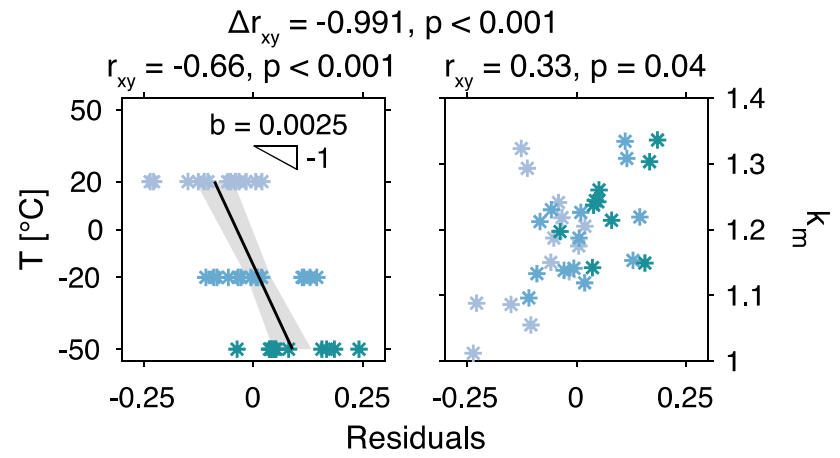

Fig. 7 Correlation between test temperature and normally distributed residuals, and comparison of correlation with stress magnification factors $k_{m}$ of all test series that include three different test temperatures; adopted from Braun [23] 
other weld details with fatigue failure at the weld toes (transversal stiffeners and butt-welded joints) show moderate correlations-with the exception of S235 butt-welded joints, for which no correlation is observed. The negative correlations indicate that a higher fatigue strength is observed at sub-zero temperatures (positive residuals correspond to result on the right side of the normal distribution) [23].

To quantify the effect of the test temperature, the steepness of the correlation best fit is determined-see Fig. 7, represented by a black line with a $95 \%$ confidence interval in grey. The slope of the best fit $b$ is determined from the correlation coefficients and the standard deviations around the $\mathrm{x}$ - and y-axes $\left(S D_{x}\right.$ and $\left.S D_{y}\right)$ by:

$b=r_{x y}\left(\frac{S D_{y}}{S D_{x}}\right)$

There are differences in the steepness of the correlation best fits; however, the order of magnitude is similar for all test series that showed a moderate to strong correlation. In general, a higher value $b$ confirms a stronger influence of the test temperature on fatigue life.

The reason for the significantly stronger correlation for the cruciform joints is thought to be related to the smaller number of influencing factors. The fatigue strength of cruciform joints showing weld root failure is almost exclusively defined by crack propagation from sharp notches. Hence, the scatter of fatigue strength for such weld details is usually lower compared with weld details showing weld toe failure. This can clearly be seen from Fig. 4. Additionally, the range of stress magnification factors $k_{m}$ for of the $\mathrm{S} 235$ joints is comparably low and does not seem to affect the fatigue strength much, see [52]. Comparing the slope of the linear fits of S235 and S500 cruciform joints, a shallower slope (higher $b$ ) is observed for the $\mathrm{S} 235$ joints. This result agrees well with the change of mean fatigue strength, see Fig. 5.

For both cruciform joint datasets, it is observed that the variables are significantly different as the outcome of the $Z$ test is statistically significant with $\left(\left|\Delta r_{x y}\right|>0.9\right.$ and $p<0.001$ ). In fact, the two variables (stress magnification factor and test temperature) account for more than $90 \%$ of the variability of the residuals in both cases, i.e., the location within the normal distribution of residuals of logarithmic number of cycles to failure [23]. Again, this result is expected due to sharp weld root radii and a generally small scatter of fatigue test results for this weld detail. This is evidently related to the low ratio of fatigue crack initiation to growth period for cruciform joints compared with weld details that show crack initiation at the weld toes, see Fischer et al. [53]. What is, however, interesting to note is the moderate positive correlation between the residuals of logarithmic number of cycles to failure $N_{f}$ and the stress magnification factors $k_{m}$ for the $\mathrm{S} 500$ cruciform joints. The positive correlation seems to be related to a few test results with high stress magnification factors $k_{m}$. Those were, however, all tested at $-50{ }^{\circ} \mathrm{C}$. The correlation might be coincidental, as no test results are available for S500 cruciform joint specimens with $k_{m}<1.1$.

For the other weld details, the $\mathrm{Z}$ test results show lower differences in correlation coefficients. This is probably related to the fact that other influencing factors affect fatigue strength and, thereby, also the residuals of logarithmic number of cycles to failure $N_{f}$ and the effect of a moderate correlation to the stress magnification factors $k_{m}$ for the majority of other test series. In fact, the highest correlations between the residuals of logarithmic number of cycles to failure $N_{f}$ and the stress magnification factors $k_{m}$ are observed for the butt-welded joints. This agrees with recent results that showed a strong influence of stress-magnification factors if fixed clamps are used in fatigue tests, see Braun et al. [54].

Next, bootstrapping of the samples is performed to determine the variance of the obtained correlation coefficients. Bootstrapping methods are statistical algorithms that are based on random sampling with replacement. The advantage of bootstrapping of small samples is that the variance of a sample can be determined without the need to know the exact distribution of the original sample; however, in order to determine the variance, the process has to be repeated a large number of times. A typical number of repetitions is 1000 [55]. Hence, a probability density of the original sample or a confidence interval of a quantity like the correlation coefficient $r_{x y}$ is obtained. The estimate of the correlation coefficient of the real population $\vec{r}_{x y}^{*}$ corresponds to the mean of the bootstrapped probability density estimates. [23]

The results of the bootstrapped samples are presented in Fig. 8 including the fitted normal distributions (solid line) to the bootstrapped data. From the distribution, the estimate of the correlation coefficient $\bar{r}_{x y}^{*}$ and the standard deviation, i.e., the standard error $S E$, are determined. The $95 \%$ confidence interval of the mean value (estimate of the correlation coefficient $\vec{r}_{x y}^{*}$ ) corresponds to $1.96 \times S E$ if the sampling distribution fits a normal distribution [56]. Indeed, the bootstrapped estimates seem to match a normal distribution well.

Comparing the estimate of the correlation coefficient $\bar{r}_{x y}^{*}$ with the Pearson correlation coefficients $r_{x y}$ for the number of cycles to failure $N_{f}$ and the test temperatures $T$, a good agreement is observed for all datasets. In fact, the maximum deviation between both is only 0.01 ; however, more importantly, low standard errors and confidence intervals are calculated for all datasets. The confidence interval is a suitable measure to determine whether a dataset is large enough to come to certain conclusions. As the actual variance of a bootstrapped distribution is approximately equal to the bootstrapped variance [57], direct conclusions about the quality and amount of data are possible. Again, the lowest scatter (i.e., standard error) 
Fig. 8 Histograms of probability density of correlation coefficients obtained from 1000 bootstrap samples from the initial sample size of a butt-welded joint, $\mathbf{b}$ transversal stiffener, and $\mathbf{c}$ cruciform joint test data-with estimates of the correlation coefficient $\bar{r}_{x y}^{*}$ and the standard errors $S E$; extended from Braun [23]

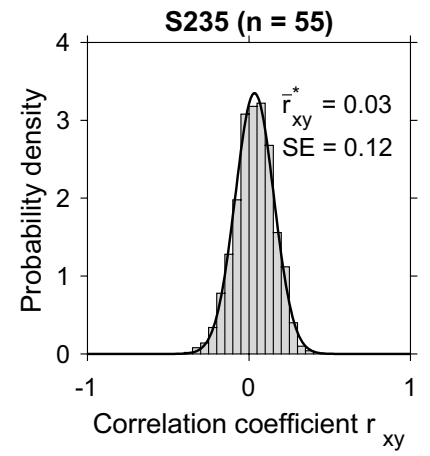

(a) Butt-welded joints
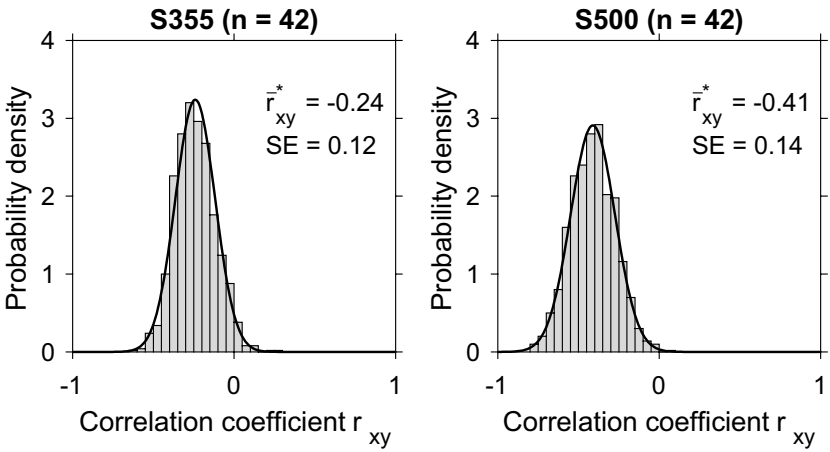

(b) Transversal stiffeners
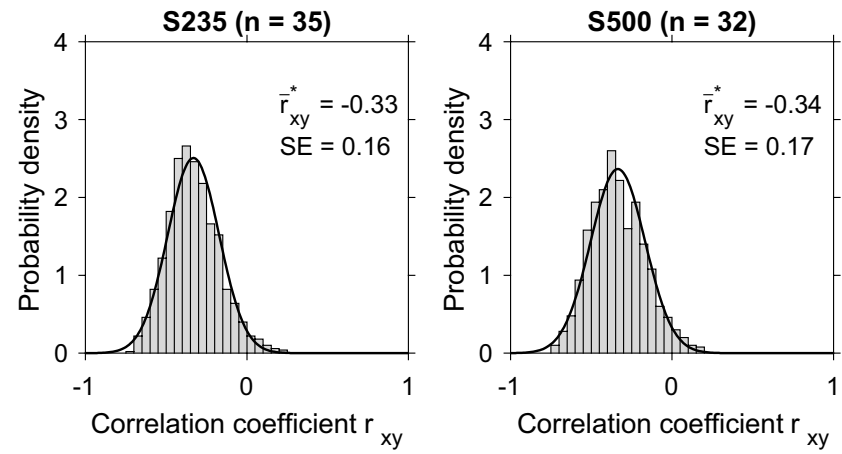

(c) Cruciform joints
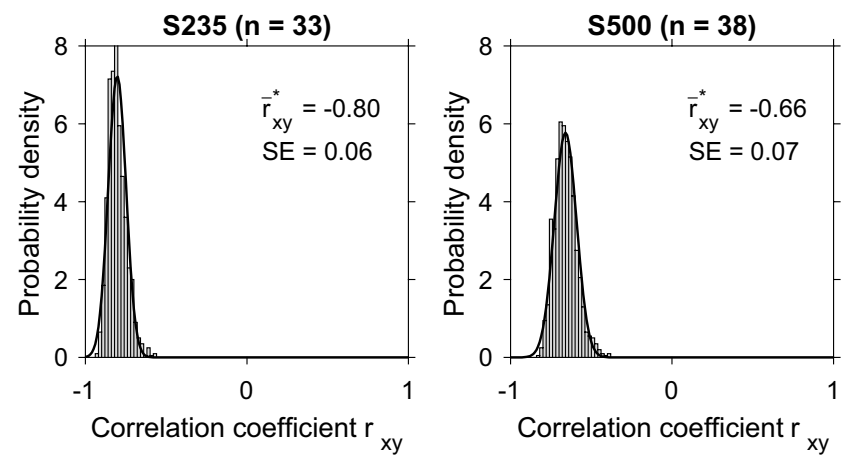

is observed for the cruciform joints. The standard error of the butt-welded joint specimens and the transversal stiffener are about two and three times larger than for the cruciform joints, respectively. This indicates that the data was in many cases sufficient to confirm moderate correlations, but should have been larger to result in such low standard errors as observed for the cruciform joints. This is exacerbated by the fact that the range of bootstrapped correlation coefficients extends from strong correlations to no correlation. Finally, the assessment and in particular the data for cruciform joints does, however, confirm the correlation between the test temperature and the residuals of logarithmic number of cycles to failure and consequently the substantial effect of test temperature on fatigue life.

\section{Discussion}

The experimental test results show a clear trend of increasing fatigue strength with decreasing test temperature. By means of statistical assessment, a correlation between test temperature and fatigue life is verified for the majority of weld details and steel types. This result is in line with studies on FCG rate testing of base materials as well as $\mathrm{S}-\mathrm{N}$ fatigue tests of welded joints at sub-zero temperatures $([7,10,12,15-17])$.

The increase in fatigue strength at sub-zero temperatures is found to be similar for all weld details and steel types. Interestingly, the highest relative increase was 
obtained for cruciform joints with weld root failure, but the highest absolute increase was observed for butt-welded joints. This confirms an assessment by Alvaro et al. [19] with regard to differences in crack initiation and propagation behavior at sub-zero temperatures. In two recent studies, Alvaro et al. [21] and Walters et al. [20] observed decrease more significant decrease of the FCG rate in the low stress-intensity factor range than in other regions of the Paris diagram, see Fig. 1. This effect could explain the difference in relative fatigue strength increase. In fact, most of the fatigue life of cruciform joints with weld root failure is determined by crack propagation with gradually increasing crack length and stress intensity factor. In contrast, the fatigue life of butt-welded joints is dominated by early crack initiation and propagating $[53,58]$.

Comparing the change in fatigue strength of weld details made of S235 normal and S500 high-strength steels, no apparent difference is observed. On the one hand, a higher relative increase is observed for S235 cruciform joints and transversal stiffeners. On the other hand, however, the relative increase of S500 butt-welded joints is slightly higher as of the S235 counterpart. Based on the statistical assessment of the test results, this could be coincidental. Higher estimates of the Pearson correlation coefficient $\bar{r}_{x y}^{*}$-for number of cycles to failure $N_{f}$ and test temperatures $T$-were determined by bootstrapping for S500 butt-welded joints and S235 cruciform joints. On the contrary, almost identical estimates were found for S235 and S500 transversal stiffeners.

The most important observation from the statistical assessment, however, is that the change in fatigue strength is evidently related to decreasing test temperatures. Especially the data of the cruciform joints showed a strong correlation between fatigue life and test temperature. For the transversal stiffeners and butt-welded joints, moderate to no correlations were observed. This is thought to be related to stronger effects of specimen misalignment and other influencing factors such as local weld geometry. The latter is practically non-existent for cruciform joints with weld root failure due to the sharp weld root notch. This result is in good agreement with FCG rate testing at sub-zero temperatures. Interestingly, the majority of studies based on S-N tests that did not observe strong temperature effects applied butt-welded joints for testing. In contrast, some studies that tested fillet-welded joints also observed significant increases in fatigue strength at sub-zero temperatures, cf. [12, 16, 42]. This explains why some studies might not have observed a temperature effect on fatigue strength, as the amount of test data was simply too small to come to this conclusion.

Additionally, differences in fatigue strength are to be expected near failure initiation locations or in areas through which cracks propagate-due to changes in the microstructure [23]. Differences in fracture mechanics properties and stacking fault energy of the microstructure could explain differences in fatigue strength between butt-welded joints and cruciform joints with weld root failure for example, see $[19,23]$; however, more research is required on this topic to resolve this knowledge gap.

The majority of state-of-the-art fatigue assessment methods for designing structures that are exposed to sub-zero temperatures are stress-based. Those methods require modification factors to account for temperature effect on fatigue strength, see Braun et al. [52]. Applying correction functions meant for high-temperature fatigue (above $100{ }^{\circ} \mathrm{C}$ ) underestimates the change in fatigue strength, see Sect. 2.2 and Braun et al. [42]. Alternatively, extensions of fatigue assessment methods-based on the micro-structural support effect hypothesis - that account for temperature effects on fatigue strength of welded joints on a sound physical basis are presented in $[33,34,59]$.

\section{Summary and conclusions}

While effects of high temperatures on material behavior are well covered in international standards and guidelines, there is no comprehensive guidance for sub-zero temperature fatigue strength assessment. In contrast, the majority of studies investigating sub-zero temperature fatigue behavior of ferritic materials observed an increase of fatigue strength before a sudden decline. More importantly, S-N test data of welded joints at sub-zero temperatures is particularly scarce. The main goal of this study is thus to presents a comprehensive review of recent test results of various weld details, tested in the range of -50 to $20^{\circ} \mathrm{C}$. This $\mathrm{S}-\mathrm{N}$ data can be used as a basis for future considerations of temperature effects in fatigue design guidelines and recommendations.

In summary, a significant fatigue strength increase was observed for welded joints at sub-zero temperatures for all three weld details (butt-welded joints, cruciform joints, and transversal stiffeners), all three steel grades $(\mathrm{S} 235 \mathrm{~J} 2+\mathrm{N}$, S355J2 + N, and S500G1 + M), and the two welding methods (sub-merged arc and flux-cored welding). The highest increase in fatigue strength was observed for the weld detail with the highest notch acuity (cruciform joints) of more than $20 \%$ at $-50{ }^{\circ} \mathrm{C}$ compared to room temperature. This result was confirmed by a rigorous statistical assessment of the test results-including the determination of Pearson correlation coefficients and bootstrapping.

Currently, international standards and guidelines do consider adverse effects of high temperature (typically above $100{ }^{\circ} \mathrm{C}$ ) on fatigue strength, but they neglect similar effects at sub-zero temperatures, cf. [27-31]. On the other hand, correction functions for high temperatures [27, 32] seem to underestimate the change in fatigue strength at sub-zero temperatures. The presented database could serve as a basis for future updates of guidelines and for standards for a more 
holistic approach to designing engineering structures that are exposed to sub-zero temperatures.

The following conclusions are drawn from the investigation:

- On average, the fatigue strength of the welded steel joints reviewed for this study increased with decreasing temperature throughout the tested range. Compared to room temperature, the relative fatigue strength increased on average by $6.3 \%$ and $15.0 \%$ at $-20{ }^{\circ} \mathrm{C}$ and $-50{ }^{\circ} \mathrm{C}$, respectively, see Fig. 3a.

- Fatigue design curves for welded joints derived from tests at room temperature underestimate the actual fatigue strength at sub-zero temperatures; this is especially true for weld details with sharp notches such as cruciform joints showing weld root failure, see Fig. 3b.

- Comparing the fatigue strength increase at sub-zero temperatures to controls at room temperature, the highest relative increase of $25.5 \%$ was obtained for the weld details with the highest notch acuity (cruciform joint with weld root failure), but the highest absolute increase was observed for the weld details with the lowest notch acuity (butt-welded joints).

- The effect of test temperature on fatigue strength was statistically confirmed by determining the Pearson correlation coefficients between test temperature and number of cycles to failure and by bootstrapping.

- Various influencing factors affect fatigue life of welded joints. It is hence not surprising that the strongest correlation between number of cycles to failure and test temperature was observed for the weld detail with the highest notch acuity and the lowest influence of geometry-related factors (cruciform joints showing weld root failure).

- Finally, bootstrapping of the data confirmed that the amount of data gathered for this study was sufficient to draw these conclusions. Furthermore, the confidence interval of correlations between the number of cycles to failure and the test temperature is larger for weld details with lower notch acuity. Hence, more test data is required (e.g., for butt-welded joints compared to filletwelded joints) to verify the temperature effect on fatigue strength. This explains why some studies-in particular those testing butt-welded joints-showed ambiguous results instead of confirming the temperature effect.

\section{Outlook}

A better understanding of extreme temperature conditions is decisive for the structural integrity of engineering structures in Arctic regions. This study confirmed an increasing constant-amplitude fatigue strength of welded joints with decreasing temperature; however, this effect is not yet considered in international standards and design guidelines. To verify this effect under realistic loading conditions, this finding should be substantiated by variable amplitude loading tests, which is part of an ongoing project, see [4, 60, 61].

Acknowledgements I would like to thank all contributors and coauthors of the papers that built the basis for this study.

Funding Open Access funding enabled and organized by Projekt DEAL. The work was performed within the research project ESM-50 "Fatigue of welded structures at sub-zero temperatures," funded by the German Research Association of the Working Group of the Iron- and Metal-processing Industry e.V. as part of the Donors' Association for the Promotion of Sciences and Humanities in Germany under project number AVIF-No. A 301 and by the German Federal Ministry for Economic Affairs and Energy (BMWi) in the framework of MarTERA ERA-NET Cofound scheme (MarTERA - FATICE (03SX465B)).

\section{Declarations}

Competing interests The author declares no competing interests.

Open Access This article is licensed under a Creative Commons Attribution 4.0 International License, which permits use, sharing, adaptation, distribution and reproduction in any medium or format, as long as you give appropriate credit to the original author(s) and the source, provide a link to the Creative Commons licence, and indicate if changes were made. The images or other third party material in this article are included in the article's Creative Commons licence, unless indicated otherwise in a credit line to the material. If material is not included in the article's Creative Commons licence and your intended use is not permitted by statutory regulation or exceeds the permitted use, you will need to obtain permission directly from the copyright holder. To view a copy of this licence, visit http://creativecommons.org/licenses/by/4.0/.

\section{References}

1. Kim J-H, Kim Y (2019) Numerical simulation on the ice-induced fatigue damage of ship structural members in broken ice fields. Mar Struct 66:83-105. https://doi.org/10.1016/j.marstruc.2019. 03.002

2. Zhang DY, Wang G, Yue QJ (2018) Evaluation of ice-induced fatigue life for a vertical offshore structure in the Bohai Sea. Cold Reg Sci Technol 154:103-110. https://doi.org/10.1016/j.coldr egions.2018.05.012

3. Nord TS, Samardžija I, Hendrikse H, Bjerkås M, Høyland KV, Li H (2018) Ice-induced vibrations of the Norströmsgrund lighthouse. Cold Reg Sci Technol 155:237-251. https://doi.org/10. 1016/j.coldregions.2018.08.005

4. Høyland KV, Nord T, Turner J, Hornnes V, Gedikli ED, Bjerkås M, Hendrikse H, Hammer T, Ziemer G, Stange T, Ehlers S, Braun M, Willems T, Fischer C (2021), Fatigue damage from dynamic ice action - The FATICE project. 26th International Conference on Port and Ocean Engineering under Arctic Conditions, Moscow, Russia

5. von Bock und Polach RUF, Klein M, Kubiczek J, Kellner L, Braun M, Herrnring H (2019) State of the art and knowledge gaps on modelling structures in cold regions. ASME 2019 38th International Conference on Ocean, Offshore and Arctic Engineering 
Glasgow, Scotland. OMAE2019-95085. https://doi.org/10.1115/ OMAE2019-95085

6. Baek JH, Kim CM, Kim WS, Kho YT (2001) Fatigue crack growth and fracture toughness properties of 304 stainless steel pipe for LNG transmission. Met Mater Int 7:579-585. https://doi. org/10.1007/Bf03179257

7. Bridges R, Zhang S, Shaposhnikov V (2012) Experimental investigation on the effect of low temperatures on the fatigue strength of welded steel joints. Ships Offshore Struct 7:311-319. https:// doi.org/10.1080/17445302.2011.563550

8. Jeong D, Lee S, Seo I, Yoo J, Kim S (2015) Fatigue crack propagation behavior of Fe24Mn steel weld at 298 and $110 \mathrm{~K}$. Met Mater Int 21:22-30. https://doi.org/10.1007/s12540-015-1004-x

9. Jung D-H, Kwon J-K, Woo N-S, Kim Y-J, Goto M, Kim S (2013) S-N Fatigue and fatigue crack propagation behaviors of X80 steel at room and low temperatures. Metall Mater Trans A 45:654-662. https://doi.org/10.1007/s11661-013-2012-4

10. Kang KW, Goo BC, Kim JH, Kim DK, Kim JK (2009) Experimental investigation on static and fatigue behavior of welded SM490A steel under low temperature. Int J Steel Struct 9:85-91. https://doi.org/10.1007/Bf03249483

11. Kim S, Jeong D, Sung H (2018) Reviews on factors affecting fatigue behavior of high-Mn steels. Met Mater Int 24:1-14. https:// doi.org/10.1007/s12540-017-7459-1

12. Li ZR, Zhang DC, Wu HY, Huang FH, Hong W, Zang XS (2018) Fatigue properties of welded Q420 high strength steel at room and low temperatures. Constr Build Mater 189:955-966. https://doi. org/10.1016/j.conbuildmat.2018.07.231

13. Liao XW, Wang YQ, Qian XD, Shi YJ (2018) Fatigue crack propagation for Q345qD bridge steel and its butt welds at low temperatures. Fatigue Fract Eng M 41:675-687. https://doi.org/ 10.1111/ffe. 12727

14. Shulginov B, Matveyev V (1997) Impact fatigue of low-alloy steels and their welded joints at low temperature. Int J Fatigue 19:621-627. https://doi.org/10.1016/s0142-1123(97)00066-2

15. Zhao W, Feng G, Liu W, Ren H (2020) Research on Fatigue Properties of Typical Welded Joints of DH36 Steel at $-60{ }^{\circ} \mathrm{C}$. Appl Sci, 10. https://doi.org/10.3390/app10113742

16. Wang YT, Liu JJ, Hu JJ, Garbatov Y, Soares CG (2021) Fatigue strength of EH36 steel welded joints and base material at lowtemperature. Int J Fatigue, 142. https://doi.org/10.1016/j.ijfatigue. 2020.105896

17. Viespoli LM, Leonardi A, Cianetti F, Nyhus B, Alvaro A, Berto F (2019) Low-temperature fatigue life properties of aluminum butt weldments by the means of the local strain energy density approach. Mater Des Process Commun 1:e30. https://doi.org/10. $1002 / \mathrm{mdp} 2.30$

18. Kawasaki T, Nakanishi S, Sawaki Y, Hatanaka K, Yokobori T (1975) Fracture toughness and fatigue crack propagation in high strength steel from room temperature to $-180^{\circ} \mathrm{c}$. Eng Fract Mech 7:465-472. https://doi.org/10.1016/0013-7944(75)90047-8

19. Alvaro A, Akselsen OM, Ren XB, Kane A (2014) Fundamental aspects of fatigue of steel in Arctic applications. The 24th International Ocean and Polar Engineering Conference, Busan, Korea

20. Walters CL, Alvaro A, Maljaars J (2016) The effect of low temperatures on the fatigue crack growth of S460 structural steel. Int J Fatigue 82:110-118. https://doi.org/10.1016/j.ijfatigue.2015.03. 007

21. Alvaro A, Akselsen OM, Ren XB, Perillo G, Nyhus B (2017) On the relation between fatigue and static ductile to brittle transition for weld simulated $420 \mathrm{MPa}$ structural steel. The 27th International Ocean and Polar Engineering Conference. San Francisco

22. Hauge M, Maier M, Walters CL, Østby E, Kordonets SM, Zanfir C, Osvoll H (2015) Status update of ISO TC67/SC8/WG5: materials for arctic applications. The 25th International Ocean and Polar Engineering Conference, Kona, Hawaii, USA
23. Braun M (2021) Assessment of fatigue strength of welded steel joints at sub-zero temperatures based on the micro-structural support effect hypothesis. Doctoral Thesis. Konstruktion und Festigkeit von Schiffen M-10, Technische Universität Hamburg. https:// doi.org/10.15480/882.3782

24. Ehlers S, Østby E (2012) Increased crashworthiness due to arctic conditions - the influence of sub-zero temperature. Mar Struct 28:86-100. https://doi.org/10.1016/j.marstruc.2012.05.004

25. Paik JK, Kim KJ, Lee JH, Jung BG, Kim SJ (2017) Test database of the mechanical properties of mild, high-tensile and stainless steel and aluminium alloy associated with cold temperatures and strain rates. Ships Offshore Struct 12:S230-S256. https://doi.org/ 10.1080/17445302.2016.1262729

26. Braun M, Kahl A, Willems T, Seidel M, Fischer C, Ehlers S (2021) Guidance for material selection based on static and dynamic mechanical properties at sub-zero temperatures. J Offshore Mech Arct Eng 143:1-45. https://doi.org/10.1115/1.40492 52

27. Hobbacher AF (2016) Recommendations for fatigue design of welded joints and components. 2nd ed., Springer International Publishing Switzerland

28. BS 7910:2013+A1:(2015) Guide to methods for assessing the acceptability of flaws in metallic structures (2015). London, UK

29. EN ISO 19906:(2019): Petroleum and natural gas industries arctic offshore structures. Brussels, Belgium

30. ShipRight Design and construction Fatigue Design Assessment FDA ICE Fatigue Induced by Ice Loading (2011). London, UK

31. BS EN 1993-1-9:2005 - Eurocode 3 (2008) Design of Steel Structures - Part 1-9: Fatigue. Brussels, BE

32. FKM-Richtlinie (2012) Rechnerischer Festigkeitsnachweis für Maschinenbauteile aus Stahl, Eisenguss- und Aluminiumwerkstoffen. VDMA-Verlag, Frankfurt/Main

33. Braun M, Ehlers S (2021) Review of methods for the high-cycle fatigue strength assessment of steel structures subjected to subzero temperature. Marine Structures, submitted for publication.

34. Braun M, Fischer C, Fricke W, Ehlers S (2020) Extension of the strain energy density method for fatigue assessment of welded joints to sub-zero temperatures. Fatigue Fract Eng M 43:28672882. https://doi.org/10.1111/ffe.13308

35. DNVGL-OS-B101, Metallic materials. (2018). DNV GL AS.

36. Gubeljak N, Legat J, Koçak M (2002) Effect of fracture path on the toughness of weld metal. Int J Fracture 115:343-359. https://doi.org/10.1023/a:1016368019571

37. Coronado JJ, Cerón C (2010) Fracture mechanisms of CTOD samples of submerged and flux cored arc welding. Theoret Appl Fract Mech 53:145-151. https://doi.org/10.1016/j.tafmec.2010. 03.008

38. Vojvodic Tuma J, Sedmak A (2004) Analysis of the unstable fracture behaviour of a high strength low alloy steel weldment. Eng Fract Mech 71:1435-1451. https://doi.org/10.1016/s00137944(03)00166-8

39. Renken F, von Bock und Polach RUF, Schubnell J, Jung M, Oswald M, Rother K, Ehlers S, Braun M (2021) An algorithm for statistical evaluation of weld toe geometries using laser triangulation. International Journal of Fatigue, 149. https://doi.org/10. 1016/j.ijfatigue.2021.106293

40. Schubnell J, Jung M, Le CH, Farajian M, Braun M, Ehlers S, Fricke W, Garcia M, Nussbaumer A, Baumgartner J (2020) Influence of the optical measurement technique and evaluation approach on the determination of local weld geometry parameters for different weld types. Welding in the World 64:301-316. https://doi.org/10.1007/s40194-019-00830-0

41. Merkblatt DVS 2403 Empfehlungen für die Durchführung, Auswertung und Dokumentation von Schwingfestigkeitsversuchen an Schweißverbindungen metallischer Werkstoffe (2019) DVS Media GmbH, Düsseldorf 
42. Braun M, Scheffer R, Fricke W, Ehlers S (2020) Fatigue strength of fillet-welded joints at subzero temperatures. Fatigue Fract Eng M 43:403-416. https://doi.org/10.1111/ffe.13163

43. Braun M, Milaković A-S, Ehlers S, Kahl A, Willems T, Seidel M, Fischer C (2020) Sub-zero temperature fatigue strength of butt-welded normal and high-strength steel joints for ships and offshore structures in arctic regions. ASME 2020 39th International Conference on Ocean, Offshore and Arctic Engineering, Fort Lauderdale, FL, USA. OMAE2020-18892. https://doi.org/ 10.1115/omae2020-18892

44. Braun M, Ahola A, Milaković A-S, Ehlers S (2021) Comparison of local fatigue assessment methods for high-quality butt-welded joints made of high-strength steel. Forces in Mechanics, submitted for publication.

45. Anderson TW, Darling DA (1952) Asymptotic theory of certain "goodness of fit" criteria based on stochastic processes. Ann Math Stat 23:193-212

46. Wilker H (2018) Statistische Hypothesentests in der Praxis: Leitfaden zur Anwendung von Hypothesentests für die Analyse von Unterschieden, Übereinstimmungen, Zugehörigkeiten, Zufälligkeiten und Zusammenhängen. 3. ed., Books on Demand

47. Haibach E (2006) Betriebsfestigkeit: Verfahren und Daten zur Bauteilauslegung, 3rd edn. Springer-Verlag, Berlin, Heidelberg, New York

48. Pearson K (1895) Notes on Regression and Inheritance in the Case of Two Parents. In: Proceedings of the Royal Society of London, Taylor \& Francis, 240-242

49. Steiger JH (1980) Tests for comparing elements of a correlation matrix. Psychol Bull 87:245-251. https://doi.org/10.1037/00332909.87.2.245

50. Meng X-L, Rosenthal R, Rubin DB (1992) Comparing correlated correlation coefficients. Psychol Bull 111:172-175. https://doi. org/10.1037/0033-2909.111.1.172

51. Ratner B (2009) The correlation coefficient: Its values range between $+1 /-1$, or do they? J Target Meas Anal Mark 17:139_ 142. https://doi.org/10.1057/jt.2009.5

52. Braun M, Milaković A-S, Renken F, Fricke W, Ehlers S (2020) Application of local approaches to the assessment of fatigue test results obtained for welded joints at sub-zero temperatures.
International Journal of Fatigue, 138. https://doi.org/10.1016/j. ijfatigue.2020.105672

53. Fischer C, Fricke W, Rizzo CM (2016) Fatigue tests of notched specimens made from butt joints at steel. Fatigue Fract Eng M 39:1526-1541. https://doi.org/10.1111/ffe.12473

54. Braun M, Milaković A-S, Andresen-Paulsen G, Fricke W, Ehlers S (2020) A novel approach to consider misalignment effects in assessment of fatigue tests. Ship Technology Research, submitted for publication

55. Pattengale ND, Alipour M, Bininda-Emonds ORP, Moret BME, Stamatakis A (2009) How Many Bootstrap Replicates Are Necessary? In, Springer Berlin Heidelberg, Berlin, Heidelberg, 184-200

56. Pham H (2006) Springer Handbook of Engineering Statistics. Springer, London

57. Wu C, Thompson ME (2020) Sampling Theory and Practice. Springer International Publishing, Cham

58. Maddox SJ (2002) Fatigue Strength of Welded Structures. 2nd ed., Woodhead Publishing

59. Braun M, Milaković A-S, Ehlers S (2021) Fatigue Assessment of Welded Joints at Sub-Zero Temperatures by means of Stress Averaging Approach. Ships Offshore Struct 16:216-224. https:// doi.org/10.1080/17445302.2021.1906194

60. Milaković A-S, Braun M, Willems T, Hendrikse H, Fischer C, Ehlers S (2019) Methodology for estimating offshore wind turbine fatigue life under combined loads of wind, waves and ice at sub-zero temperatures. International Conference on Ships and Offshore Structures ICSOS 2019 Cape Carnival, USA

61. Braun M, Stange T, Ziemer G, ter Veer KF, Willems T, Kubiczek JM, von Bock und Polach RUF, Ehlers S (2021) Einfluss von Minusgraden und variablen Lastamplituden infolge Seegangs- und Eislasten auf den Entwurf von Offshore Windenergieanlagen. 9. Fachtagung Bemessung und Konstruktion, Halle, Germany

Publisher's note Springer Nature remains neutral with regard to jurisdictional claims in published maps and institutional affiliations. 